\title{
(G)IZADIRANTZ: TOWARDS THE CHARGED VOID
}

\section{Imanol Esperesate Azpiazu}

Euskal Herriko Unibertsitatea. Eskultura Saila. Doktoregaia

\section{Laburpena}

Gizadiak, ustezko aurrerabidearen ardatz izan diren eta izaten jarraitzen duten autoaz eta energia nuklearraz baliatuz pausoa etengabe lasterragotzeko duen joerak, izadiaren betiereko erritmoa hautsi eta izadia atzean uztea dakar. Gizakiaren esku-hartze desegokietatik haraindi, izadiaren aurrean gizadiak duen jarrera dago, balantzaren bi aldetan bata zein bestea bereiztean eta bien artean oreka mantentzean datzana. Balantzaren bi aldeek eta paraleloan dauden edo teilakatzen diren bi bideek iturri beretik edaten dute ura. Teilakatze/oreka horrek eragin zuzena dauka gaur egungo paisaiaren eraikuntzan non gizakiak nahitaez bere eskuaren arrastoa utzi behar duen bere beharrak asetzeko afanean. Horren aurrean, errail-bakarreko-bideari ekin behar diogu, zuhaiztiak inguratzen duen zelaia eta lantegia gauza bera baitira, guztiz bateragarriak. Era horretan, izadiak gizadia ordezkatuko du eta ezin atzeragarriak diren hondamendiak saihestuko eta berdeguneak espaloiko lauzak bezala zapalduko ditugu.

\section{Hitz gakoak: GIZADIA; IZADIA; TEILAKATZE/OREKA; PAISAIAREN ERAIKUNTZA; ERRAIL-BAKARREKO-BIDEA}

\section{(G)IZADIRANTZ: TOWARDS THE CHARGED VOID}

\section{Abstract}

Humanity, taking the advantage of the key elements of the development such as, cars and nuclear energy in order to accelerate its steps constantly, has broken nature's constant rhym and has overtaken it. Beyond human's inadequate interventions, there is the human's behaviour regarding to nature which consists of separating both of them in a scale and trying to keep them in equilibrium. Both sides of the scale as well as the ways that are in parallel or are overlapped, all of them come from the same place. There is a relevant connection between the overlap/equilibrium action and the constraction of the landscape at the present time where the human being always leaves his/her marks on it in order to meet his /her constant needs. In contrast, we must go throuh the way-with-one-lane because the field which is surrounded by trees and a factory are the same, compatible with each other. Consequently, nature will replace humanity and we will avoid irreversible disasters and we will step on both the pavement and the fields.

\section{Keywords: HUMANITY; NATURE; OVERLAP/EQUILIBRIUM; CONSTRACTION OF THE LANDSCAPE; WAY-WITH-ONE-LANE}

\footnotetext{
Esperesate Azpiazu, Imanol. 2016. “(G)izadirantz: Towards the charged void”. AusArt 4(1): pp-pp. 227-236 D0I: 10.1387/ausart.16712
}

\section{AUSART}


Gure hirietan berdeguneak non-nahi daude, orbain txiki eta lausoak espaloiaren grisarekin eta errepideen galipotaren beltzarekin lehiatzen dira, hasi aurretik, oinarrietatik galduta duten norgehiagoka zentzugabe batean. Norgehiagoka erpinetatik esku batzuek astindutako eta beraiek beraien beharretara jositako sare batekin aldera genezake: sareko hutsuneak desberdinak izateaz gain, garaian garaira egokituko lirateke, berdeguneak parke handietan hedatzeraino edo espaloien jarraitutasuna eteten duten lorontzi izaerako azaleretan itotzeraino. Azken horietan espaloiko lauzen eta berdegunearen arteko muga ezartzen duen koskak berdegunea zedarritzen du eta hori gutxi balitz, eskailera maila baten altuerako burdinazko hesi batek muga gehiago mugatzen du. Nahikoa da ehundura desberdineko bi material bata bestearen ondoan jartzea bien arteko muga ezin hobeto marrazteko. Nahikoa da marraztutako lerro horri bolumena ematea berdegunea ez zapaltzeko eta nahikoa da itzala sortzen duen lerroan hesi txiki bat bermatzea estropezu egin eta berdegunean erori eta muturrekoa hartzeko. Era berean muturrekoa hartuko genuke berdegunean iltzatutako kartel batek berdegunea ez zapaltzera gonbidatuko bagintu. Ez gaitezen engainatu, koska, hesia eta kartela gauza bera dira, guztiak debekuak, guztiak oztopoak, guztiak berdegunea zapaltzearen ekintza soil eta arrunta bazterreko, legez kontrako, begirunerik gabeko eta indarkeriazko ekintza isolatu batean bilakatzen dutenak.

Lauzaren eta berdegunearen arteko eta loditu eta lausotu daitekeen lerro horrek (g)izadiak ()izadiaren aurrean duen jarrera islatzen du. Gizakia eta natura gauza bera ez diren eta gizakia naturaren gainetik dagoen ideia benetan ahuletik abiatuta, natura gure beharrak asetzeko erabiltzeko zilegitasun osoa duen arren, zaindu beharreko altxorra dela sinetsarazi digute.

Euskaltzaindiaren hiztegiaren arabera, izadia eta natura hitzek esanahi bera dute gizadi eta gizateri hitzek bezala. Bi hitzak parez pare jarriz gero, izadiak izaki bizidun guztiak beregain hartzen dituen bitartean gizadia, soilik, gizakien multzora mugatzen da. Izadiaren esanahia izadiari $g$ hizki soil bat aitzinetik atxikita erabat iraultzen da: hasierako orokortasuna esparru jakin batera laburtu eta nik aldarrikatzen dudan jatorrizko orokortasun hori gutxietsi egiten da.

Izan ere, gizakia ez da izadiaren atal sentitzen, izadiak inguratzen duela jakin badakien arren. Are gehiago, gizadiaren atal bakarrik ikusten du bere burua eta horregatik baliatzen da gizadi terminoaz, izadiaz beharrean, bere buruaz ari denean eta horregatik tematzen da burugogor lauzazko espaloietan soilik ikusteko diren berdeguneak jartzen, inguruan, distantzia laburrera erabili daitekeen berdegune handi bat duenean. Gure buruaren gatibu gara, 
inguratzen gaituen airea arnastu eta gure baitan itotzen gara. Aireak abian jartzen du izadia, hauspotzen du zapaltzen dugun lurzorua eta abiada hartzean astintzen ditu balkoietatik eta teilatuetatik burua ateratzen duten koloretako oihalak. Aireak ere astintzen zuen bazter batean mailua eta igitaiaren zigilua zuen eta Txernobyleko laugarren erreaktorearen estalkian, sarkofagoaren eta garbiketa lanak amaitzean, igo zuten oihal gorria, erradioaktibitatearen aurkako garaipen ikur gisa. Aireak, batere ongietorria ez zen ezusteko bisitari ikusezin, aurkari ikusezin gisa ezagunagoa, baten bisita izan zuen orduan; bisitaria gelditzeko iritsi zen eta luzerako gainera, bidaide leiala, lagun hurkoa estutzeraino besarkatzen duten horietakoa.

Zulo beltza zirudien laugarren erreaktoreko zulotik, gori-gori zegoen sugarrak uraniozko eta grafitozko partikula erradioaktiboak jariatzen zituen. Su hura ezin zuten, inondik inora ere, eztandaren ondoren gerturatu ziren suhiltzaileek urarekin itzali (Johnson 2006). Heriozko isiltasunak, aurkari ikusezinak bezala, guztia bustitzen eta zeharkatzen zuen belarriko tinpanoak zulatu eta azala haragi eta hezur-bizian uzteraino.

Txernobyleko sarraskiaren erantzule bakarra gizadia izan zen zoritxarrez. Gizakia eta natura balantzaren plater berean egon izan balira, errua izadiari bota eta erantzukizun osoa berari leporatuko geniokeen.

Arazoak balantzaren plater bakoitzean, bakoitza bere aldetik, gizakia eta natura kokatu eta balantza ahalik eta orekatuen mantentzean datza. Oreka mantentze edo batek bestea zapaltzen duen bi bideren proposamenak galbidera garamatza, ingurura begiratzea besterik ez dago. Oreka mantentze horrek sorgin-gurpilaren gero eta antz handiagoa du: irabazi ekonomikoan oinarritzen den aurrerabideak bere bidea egiten du naturaren bideari paralelo batzuetan, horra hor gizakiaren boterearen erakusle diren lan faraonikoak, Txernobyleko laugarren erreaktorea kasu, eta naturaren bidearekin teilakatzen beste batzuetan. Teilakatzeak, kasu honetan, zentzu negatiboa du, modu apalago batean, hanka-puntetan, naturari jazartzean datzana: gure kostaldea zeharkatzen duen errepidea jar nezake adibide gisa, labarren lerrokadurari atxikitzen zaiona eta paisaiara egokitzen dena.

Kostaldea zeharkatzen duen bidearen harira, labarren goialdean txertatzen den gizakiaren bihurgunez jositako eraikuntzak itsasoari desafio egiten dio une oro: itsasoaren lurraldean sartzen da edo sartzeko keinua egiten du horrek dakartzan ondorio larriak kontuan hartu gabe askotan eta bestetan kontuan hartu bai baina akats berean eroriz. Donostiako pasealeku berria datorkit 
burura, enbatak astindutako itsaso zakarraren talkekin hondartzako hareazko gaztelua bailitzan erortzen da. Ez da gertaera jakin eta isolatu bat, denbora tarte nahiko labur baten buruan errepikatzen dena baizik, ez bakarrik pasealeku berrian, baita kostaldeko puntu askotan ere: Zarauzko malekoia, Donostiako Kontxako hondartzan dagoen bainu-etxea, duela hamar urte inguru Debatik Mutrikura itsasoarekin bat hedatzen den errepidean gertatu zen eustormaren erorketa bi norabideko bidea erabat estali zuena...

Gertaera horien aurrean eskuak burura eramaten ditugu arduratsu eta gure errua dela onartzera iritsi gaitezke, itsasoak halabeharrez berea dena berreskuratzen duela, ez garela inor baimenik eskatu gabe bere etxean sartzeko... Zalantza horiek segituan argitzen zaizkigu itsasoak hautsitako bazter horiek berreraikitzen ditugunean eta gertatutakoaz ahaztu egiten gara edo beste toki batera begiratzeko imintzioa egiten dugu, hurrengo urtean edo bi urteren buruan gauza bera gertatuko denari errezeloz so egiten diogu.

Guztiaz sinestarazten diguten horiek sorgin-gurpila etengabe biraka egoteaz arduratzen dira. Adabakien funtzioa betetzen duten behin-behineko egiturek zein irtenbideek gurpilak bira ematea ziurtatzen dute, enbatak enbata, olatuak olatu, etorkizun laburrean gauzak berdin egiten jarraitzeko. Norberak bere buruari ematen dion zilegitasun kutsua du guzti horrek, sarraskiaren aurrean errudun bakarra hatz erakuslearekin seinalatzera bultzatzen gaituena.

Behin-behinekotasunaren adibide garbia Txernobyleko laugarren erreaktoreko zuloa estaltzeko eraiki zuten sarkofagoa izan daiteke. 30 urteren buruan sarkofagoaren altzairuzko estaldura herdoilak jota dago eta itoginak non-nahi daude. Bien bitartean, magma zuri biziki erradioaktiboak bizirik lur azpian barna iragazten jarraitzen du 14 metroko sakoneran La batalla de Txernobyl, dokumentala (Johnson 2006). Horrez gain, gaur egun, 30 herrialdeetan kokatzen diren 440 zentral nuklearrek eta beste hamaika herrialdeetan barreiatuta, Txinan, Hego Korean eta Japonian, besteak beste, eraikitzen dihardutenek (Ivancic 2010, 20-1) energia nuklearraren auzia baztertzen eta aho batez bere eraginkortasuna eta zilegitasuna irmoki bermatzen dute.

Ez dut sarkofago hura eraiki zuten eta ingurua garbitzeaz arduratu ziren milaka lagunen lana gutxietsi nahi, ez da gutxiago ere, aitzitik, goraipatzen eta txalotzen dut; hiltzaile ikusezinaren aurkako borrokan beraien bizitza arriskuan jarri zuten, heriotzara eraman zitzaketen arriskuez benetan jabe ez zirela: asko zendu ziren eta oraindik bizirik dirautenek osasun arazo larriak pairatzen dituzte eta ikusteko dago ondorengo belaunaldien etorkizuna. Benetan gogoangarria da 
hondamendi hartatik bizirik atera zirenetako batek esandakoa: "Afganistaneko gerrako soldadu zaharrak oraindik bizirik daude, gu astiro higatzen ari garen bitartean" (jatorrizko aipua: Johnson 2006) (egileak itzulia).

Oreka mantentzen ahalegintzearen edo bi bideak teilakatzearen eta gizakiak bere bidea bakarrik egitearen aurrean, nik errail bakarreko izadiaren bidea aldarrikatzen dut, natura hesiaren beste aldean parez pare dagoen eta zaindu eta maite beharreko apaingarri kutsuko eszena baino, gizakiari soilik dagokion etekin ekonomiko eta ongizatetik at, bidelagun leialtzat hartzeko. Izadiak egunerokotasunari, kulturari hertsiki heldu behar dio eta bere izenak adierazten duen orokortasunaz baliatu eta gizadia ordezkatu behar du.

Errail bakarreko bideak orain arteko joera errotuak errotik ateratzea dakar, gizadia adarkatzen duen zuhaitz sendo eta zurrunaren adarrak inausi eta kimu berri malguak loratzea. Félix Guattarik bere "Hiru ekologiak" liburuan praktika sozial eta indibidualak, etika-estetikaren babesean dauden ekologia sozialaren, ekologia mentalaren eta ingurumen ekologiaren arabera berrezarri behar direla dio ([1989] 2000, 30-1).

Gizakiaren boterearen erakustaldia eta ahulezia eskutik emanda doaz. Zur beretik ezpala esan ohi dugu, gizakiaren bi aldarte guztiz antagoniko, txanponaren bi aldeak bezala, zur, gizaki edo txanpon beraren baitan. Txanpon distiratsua zen Txernobyleko laugarren erreaktorea, Sobiet Batasunaren aurrerabidearen ikurra: alde batean, ongizatea zegoen, zentral nuklearreko langileentzat eraiki zuten hiribide luze eta zabal, igerileku eta jolas parke eta guzti zituen Pripiat hiri garaikidearen irudiarekin; beste aldean, desagertzeko 24000 urte beharko zituen hiltzaile ikusezinaren mamua.

Gizadiaren ahultasuna eta ezina, agerian gelditzen dira zulo beltza ixteko eta sua itzaltzeko, eskuak bistan, inolako babesik gabe, helikopteroetatik hare toneladak bota beharrean daudenean azpian, bertatik bertara, otsoaren ahoa dakusatela eta izerdi patsetan lana bukatzean oka egiten dutenean. Ahultasuna agerian gelditzen da, erreaktoreko estalkian erradioaktibitatea igortzen duten grafitozko hondakinak estalkitik bota eta gero, batu eta zangetan ehorzteko, palak eskuan dituztela, gizakiaren beharra ezinbestekotzat jotzen denean. Ahultasuna agerian gelditzen da, hezur-haragizko pertsonek erradioaktibitateak izorratutako robotak ordezkatu behar dituztenean (Johnson 2006).

Ahultasun hitza erabili dut ahulkeri beharrean eta asmatu dudanean nago ahulkeriak zentzu negatiboa, zitala duelako; azken finean metro eta pikuko 
txotxongilo batzuk besterik ez gara, hiltzen gaituen aurkari ikusezina sortzeko gai garenak baina horri trakets aurre egin eta garaitzeko gai ez garenak. Zer pentsatua ematen du ahulkeriak ahultasuna ordezkatu dezakeen aukerak.

1953an, orduan AEBtako presidentea zen Eisenhowerek eman zuen hitzaldiaren ondoren, "Atomoak bake biderako" zeritzonak, energia nuklearra aurrerabidearen motorretako bat bilakatu zen. Aurrerabidearen ildo horretan sar genitzake errail askotako autobideek osatutako sare korapilatsuen azalera erraldoia eta autoen kopuruaren igoera nabarmena ere.

Ez da kasualitatea Alison eta Peter Smithson arkitekto eta senar-emazte ingelesek beraien asteburuetako Upper Lawn etxeari (Wiltshire 1959-62) ateratako argazki askotan beraien Citröen DS 19aren aurrealdea eta soslaia ikustea: Citröen IDaren ondorengoa eta Citröen DS Safariren aurrekaria.

Eisenhowerrek hitzaldia eman eta hiru urte beranduago, Alison eta Peter Smithsonek Etorkizunaren Etxea (1956) auto bat bailitzan proiektatu eta eraiki zuten. Izan ere, etxea eraikitzeko erabili zituzten panelen arteko lotuneen juntura malguak hozteko makinaren edo auto baten berdinak ziren. Bikoteak XX. mendeko tradizioari eusten zion baina oraingoan autoa ez zen soilik formaren eta eraikitzeko moduaren abiapuntua, mugikortasunaren ikurra ere bazen (Colomina 2004, 34). Etorkizuneko etxetik hirira salto eginez, ildo berari jarraiki, garaiko teknologiaren gizartearen beharrak asetzen eta mugimenduaren dimentsioa zekarten autobideen (elementu kitzikagarri gisa deskribatzen dituzte) sarea bereganatzen zuen hiria goraipatzen zuten. Hiriek autoa ardatz zuen mugimendu estetiko etengabean bizirik egoteak ez zituen tradiziozko herrien eta paisaia bukolikoak zapaltzen, biak ala biak bateragarriak ziren (Boyer 2011, 50-2).

Alison eta Peter Smithsonek mugimenduari buruz garai hartan idatzitakoak, 50 eta 60. hamarkadetako giroa ezin hobeto adierazten eta hirietatik at antolatzen diren zentral nuklearren eta industrialdeen sorrerarekin harreman zuzena izan dezake: "Mugikortasuna gure garaiko ezaugarri adierazkor bilakatu da. Gizarteari dagokion mugikortasuna eta mugikortasun fisikoa, biek askatasun antzeko ezaugarria daukate. Askatasun horren ikurra bakoitzak duen autoa da" (itzulpen propioa) (jatorrizko aipua: Colomina 2004, 34-5).

Alison eta Peter Smithsonen momentuarekin bat egiten zuen aurrerabidearen ikuspegia ezin dezakegu testuinguru jakin hartatik atera. Itsumustuan aurrerabidearen gurpil eroan sartu zen eta zerumuga helmuga zuen gizartearen 
emaitza da gaur egungoa, lorpenak lorpen eta akatsak akats, aurrerabidearen erritmo lasterrari orain arte eutsi dion arren atzerabide motel eta luzean sartzera zigortua dagoena.

Zapaldu ezin daitezkeen berdeguneak eta hiribildutik at dauden, autoz iritsi bidezko eta naturari bizkarra ematen dioten industrialdeak hasieran aipatutako sare sakabanatuan kateatuta daude eta elkar elikatzen diren hiriko bi atal dira. Berdeguneez luze hitz egin dut dagoeneko testuaren hasieran eta industrialdeez zehazki hitz egin ez arren, testuan zehar iragazi den aurkari ikusezinak zeharka jorratu ditu.

Gure herrietan, industrialdeak, hiri egituratik kanpo, herrenkadan dauden bi isuriko zein estalki lauko pabilioiak biltzen dituzten asfaltozko lautada handiak dira. Zelaiek eta zuhaiztiek maiz inguratzen badituzte ere, ez dituzte kontuan hartzen eta guztia autoz bertaratu eta autoz alde egitera laburbiltzen da. Asfaltozko desertua eta gutxiesten dugun oasia orpoz orpo daude.

Industrialdeek, hiri egitura barnean, ibai ertzean dauden lantegi utziak ordezkatu dituzte, arotzi fineko beirate handiak dituzten hormigoi armatuzko estalki lauko eraikinak.

Industrialdeen eta alboko zelai edo zuhaiztiaren arteko muga, berdegune eta espaloiaren artekoa bezain lodi eta garbia da. Alderantzizko bi gertaera direla esango nuke: azalera grisean azaltzen diren orbain berde txikiak batetik eta azalera berdean azaldutako orbain gris handiak bestetik.

Jada lau urte atzera egin beharrean nago Gipuzkoako garai hartako testuingurua aztertzeko. Lau urteren buruan giroa lasaitu den arren gauzak berdin jarraitzen dute. Zabor ekoizle apartak gara, supermerkatu handien janari oro plastiko ontzietan sartzeko afanak ez digu batere onik egiten eta askotan, niri dagokidanean behintzat, birziklatze hutsak supermerkatuetan bizpairu geruzek bildutako produktuak erosteko zilegitasuna eman eta sortzen ari garen zabor kopurua arrazoitzeko balio digu.

Zaborraren auziak berebiziko garrantzia eta lotura du izadiak gizadia ordezkatu behar duen ideiarekin. Duela lau urte, Gipuzkoako aldundian agintean zegoen alderdiak legealdiko programaren ardatz zuen zaborraren gaia lerro-buruan jarri zuen. Hiritar guztioi dagokigun eta hiritar guztiak erantzule garen auziari, tokian tokiko proposamen batekin irtenbidea eman nahi izatea benetan berri pozgarria eta itxaropentsua zen. Alderdiak mezua helarazten ez asmatzeak, 
hiritarren hitza kontuan ez hartzeak, eta alderdikeriak direla medio oposizioko alderdien eta eragile batzuen jazarpen basati eta bortitzak, mezua guztiz ez mamitzea ekarri zuen. Hasieran sugarra zirudien asmoa, tamalez, itzaltzen joan zen su hits bihurtu arte. Hala eta guztiz ere, ekimen hark, zaborraren inguruan genuen erantzukizunean hautsak harrotu dituelakoan nago eta bidenabar gai horrekiko sentiberatasuna eta ezagutza handitu. Ordurarte ezezaguna zitzaigun baina Kataluinian eta Europako herrialde askotan jada errotuta dagoen gai organikoak konpost bilakatzeko nozioaz jabetu ginen esaterako. Konpostaren gaiak barrenak astindu eta eragindako bulkadak konpostaren inguruan proiektu bat egitera bultzatu ninduen.

Karrera amaierako proiektu gisa (2012-2014) konpostategi bat proiektatu nuen Deba ibaiak bustitzen duen Mendaroko udalerrian, hiribildutik eta industrialdetik at, bertako hosto erorkorreko zuhaitzek (haritza nabarmentzen da) eta pinudiak inguraturiko zelai batean. Eraikina magalean hedatzen eta lurzorutik altxatzen den banda antzeko bat da, konposta egiteko prozesu lineala beregain hartzen duena eta zuhaiztiek ezarritako muga errespetatzen duena, pinu batzuk bota behar izan nituen arren. Konpostategiaz gain, konpostaren prozesuaren garapena bertatik bertara ezagutu eta lurrarekiko sentiberatasunaren sugarra piztu edo hauspotzeko, haur eta gazteentzako eskola bat proposatu nuen.

Izadiak ere lantegia besarkatzen du, lantegia ere izadia baita zuhaiztiak inguratzen duen zelaia den bezala. Lantegiak ezin dira industrialdeetara soilik mugatu, aitzitik, zelai eta zuhaiztietan barneratu behar dira.

Zelai eta berdeguneak hirietan txertatzen direla agerikoa da, horren erakusle daude paisaiaren eraikuntzak diren parkeak, zapaldu ezin diren lorategi eta berdeguneak... Neurri batean, errotutako azalera handiko parkeak salbu, etxebizitza blokeen artean, plazetan, oro har, berdeguneei dagokien espazio publikoaren gauzatzean, behin baino gehiagotan aipatu dudan lauzaren grisaren eta zelaiaren berdearen arteko talka errepikatzen da.

Ez naiz nekatzen berdeguneak, espaloi edo plazetako lauzak bezalaxe, zapaldu behar direla ahoz gora esaten eta hori egiten dudan bakoitzean, Alison eta Peter Smithsonen Robin Hood Gardens (1966-1972) etxebizitza blokeen artean hedatzen den muinoa datorkit burura eta haurrak beisbol edo cricketean jolasten ari diren irudia ere bai. "Tentsiorik gabeko" deitzen dioten erdiko berdegunea inguruko trafiko astunetik babesten duten bi etxebizitza blokek besarkatzen dute. Muinoa artifiziala da, soilik oinezkoentzat erabilgarria, eta 
etxebizitza blokeak egiteko egindako lur mugimendu eta hondakinek betetzen dute (Vidotto 1997, 128).

Alison eta Peter Smithsonek Robin Hood Gardenseko proiektua eraikitzerako Robert Smithson (1938-1973) istripu batean zendu zela hiru urte igaro ziren eta hamar urte beranduago gizadia izadiaren aurrean biluzik utzi zuen Txernobyleko ezbeharra gertatuko zen.

"Saiakera (kaxa batean harea zuria eta beltza nahastean datzana) filmatuko bagenu, filma atzekoz aurrera proiektatuz, betierekotasunen itzulgarritasuna ziur egiaztatzeko gai izango ginateke. Baina, lehenago edo beranduago, filma desegingo edo galduko eta ezin itzulizko egoera batean sartuko litzateke" (Smithson 2009, 94-5).

Robert Smithsonen hitzak irakurtzen ditudan bakoitzean oilo-ipurdia jartzen zait eta azken egunetan gogotik astindu nauen eta buruan iltzatuta gelditu zaidan Txernobyleko ezbeharrak bat-batean gogora ekarri dizkit.

Ikusten eta entzuten ez den baina ahoan metal zaporea uzten duen espezie horrek ezin itzulizko egoera batean uzten du bidean aurkitzen duen oro. Txernobyl ingurua eta bertako arnasa mapatik ezabatu zituen: gaur egun, alde egin behar izan zuten baina beranduago beraien etxeetara bueltatzea erabaki zuten pertsona bakan batzuk bizi dira hondamendiaren epizentroan, zutik irauten duten pareten artean. Beraien arnasak aurre egiten dio antza airean barreiatuta dagoen espezie ikusezinari. "Adi: gizon bat bizi da etxe honetan, ez ezazue bota" (Johnson 2006) etxe bateko horma batean idatzita dagoen erresistentzia oihua.

Zer pentsatua ematen du hiltzaile ikusezinarekin kontaktuan, segundo batzuren buruan izorratu den argazki makina batek atera dituen argazkietan, negatiboak ilun eta koloreak itzalita agertzeak edo eztandaren osteko goizean, Pripiateko kale nagusi batean filmatutako irudietan, lurzoruak argi printza biziak igortzen dituela ikusteak. Hiltzaile ikusezina hain da zitala ezen bere arrastoa epizentrotik kilometro askotara errebelatutako argazkietan uztera iritsi daitekeen. Erradioaktibitatearen arrastoa eta horrek eragindako ondorioak entropikoak direla esango nuke, xaboiarekin eta espartzuarekin gogor igurtzita eta dutxa ugari hartuta ere ezin atzeragarriak.

Mapatik ezabatu eta ahanzturan erori den inguru kutsatuak 24000 urte behar omen izango ditu atzera egin eta bizigarri izatera bueltatzeko. Betiereko 
gainbeheraren adibide hoberik ez zait une honetan bururatzen eta izadiak gizadia ordezkatzearen ezinbesteko beharraren oharpen argiagorik ezta ere.

\section{Erreferentziak}

Boyer, M. Christine. 2011. "Why do architects write? The case of Team 10 and Alison \& Peter Smithson”. In: Alison \& Peter Smithson: A Critical Anthology, Max Risselada, ed. Bartzelona: Polígrafa

Colomina, Beatriz. 2004. "Unbreathed Air". In: Smithson Alison \& Peter: From the house of the future to a house for today, Risselada, Max \& Dirk van den Heuvel, ed., 31-49 orr. Rotterdam: 010

Guattari, Pierre-Félix. (1989) 2000. Las tres ecologías, José Vasquez Pérez \& Umbelina Larraceleta, itzulpena. Valentzia: Pre-textos

Ivancic, Aleksandar. 2010. Energyscapes. Paul Hammond, itzulpena. Bartzelona: Gustavo Gili

Johnson, Thomas. 2006. "La batalla de Chernobil" [The Battle of Chernoby]. Discover Channelak igorrita. Youtube-bideoa, 1:33:15. 2012ko abuztua 22an argitaratuta. https://www. youtube.com/watch?v=uBv4IN3IGZ0

Smithson, Robert. (1966-1973) 2009. Robert Smithson: Selección de escritos. Damián Ortega, ed.; María Orvañanos, Eva Quintana Crelis, itzulpena. México DF: Alias

Vidotto, Marco. 1997. Alison+Peter Smithson: Obras y proyectos [Works and Projects]. BartzeIona: Gustavo Gili 